\title{
A tensão entre o silêncio e 0 discurso em Haneke
}

\author{
Rafael Mantovani
}

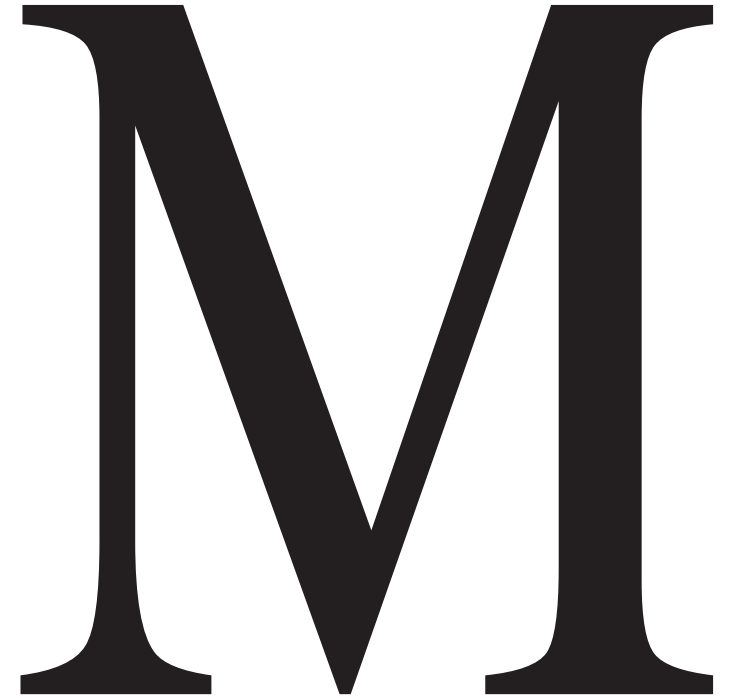

ichael Haneke é um cineasta austríaco embora nascido em Munique, em 1942 -, que estreou em 1989 com $O$ sétimo continente, ganhou notoriedade com Funny games, de 1997, e a partir de então se tornou um diretor e roteirista multipremiado. Autor provocativo, procura fazer uma arte de impacto (Speck, 2010).

Neste texto, pretendo trazer à tona a tensão entre aquilo que é discursivo e o silêncio presente em três dos seus filmes: Código desconhecido, Caché e A fita bran$c a$. Não apenas o silêncio dos atores como

RAFAEL MANTOVANI é professor do

Departamento de Sociologia e Ciência Política da Universidade Federal de Santa Catarina (UFSC). 
recurso estilístico, como é o caso do primeiro filme, mas também o tema do silêncio: silenciar-se diante da realidade, diante de algo que precisaria ter sido dito - temas presentes em Código desconhecido e Caché. E, por fim, a necessidade de falar sobre um tema - a sexualidade - em A fita branca e o completo silenciamento e abafamento com relação aos afetos.

Interessante notar que comumente fala-se a respeito do silenciamento dos oprimidos: o sufocamento das mulheres, as vozes caladas dos escravos etc. Nos filmes em questão, pode ser notado o silenciamento das classes dominantes como causa e, também, como consequência do próprio domínio, que funciona por vezes como uma dinâmica psicológica que tenta fazer acreditar ser inofensivo o próprio comportamento e, por vezes, como recrudescimento do poder.

\section{CÓDIGO DESCONHECIDO (2000)}

Código desconhecido é o filme da fase francesa de Haneke, em que ele mais abusa do "filme em fragmentos", ao contar partes da história de três agrupamentos familiares que se encontram no primeiro take do filme - depois da introdução -, um take enorme, de mais de oito minutos. São famílias de algum lugar da África (não se especifica de onde), da Romênia e da França. Depois desse primeiro take, apenas o rapaz da família africana se encontra com o casal francês em um bar, mas sem interação. Haneke não faz as histórias se cruzarem novamente nem lhes dá desfecho algum. Mesmo assim, não deixa de ser um filme interessante que trata do que Christophe Dejours (2007) chamaria de "antolho voluntário" e "retraimento da consciência subjetiva" por parte da personagem interpretada por Juliette Binoche, diante da xenofobia e do racismo em uma França pretensamente acolhedora e indiferente a origens e cores de pele.

Concisamente, depois de uma introdução em que crianças surdas brincam de mímica e nenhuma adivinha (o que já revela que a incomunicabilidade permeará o filme), o longo take em que as três "famílias" se encontram começa quando Anne (Binoche) recebe em sua casa, em Paris, o seu genro Jean (Alexandre Hamidi), que diz que precisa de um lugar para morar, pois tinha saído de casa. Compra-lhe algo para comer e o deixa. $\mathrm{O}$ rapaz sai comendo pelas ruas e atira detestavelmente o lixo sobre uma pedinte, Maria (Luminita Gheorghiu). Amadou (Ona Yenke) vê a cena, vai atrás do rapaz e exige que ele se retrate com a senhora. Ele se recusa, eles começam a se confrontar, as pessoas ao redor começam a notar a briga e Amadou lhe dá um tapa no rosto. Anne volta, pergunta o que houve e Jean lhe diz que o rapaz tinha batido nele. Ora, o que aconteceu, na versão cínica dele, não foi estarem se agredindo por causa da atitude dele, mas, sim, porque Amadou lhe teria dado um tapa. Chega a polícia e pede os documentos de todos, que são levados à delegacia. Nesse ínterim, Amadou tem dificuldade de explicar o que houve, mas Anne presencia duas vezes em que ele diz que Jean teria humilhado a senhora: na primeira, é realmente um pouco difícil de reter a informação, mas na segunda, diante da polícia, ele o faz bastante pausadamente. Essa senhora, que pedia esmolas, era uma imigrante ilegal romena e, depois saberemos, será deportada. É o paradoxo das consequências: Amadou quis fazer algo naquela 
situação em que a vítima era Maria, mas teria sido melhor se não tivesse feito nada.

O único outro momento em que há um encontro entre alguns desses grupos é em um bar: Amadou está com uma garota e Anne percebe a presença do rapaz. Volta para a mesa em que está com o seu grupo e chama a atenção do seu namorado, Georges (Thierry Neuvic): "Olha ali, perto da parede, o garoto negro que discutiu com Jean. Não deixe ele nos ver!". Para ela, aquele rapaz era "o garoto negro que discutiu com Jean", e deve ser perigoso: "Não deixe que ele perceba a nossa presença". Há aí um "antolho voluntário", um desvio deliberado de atenção do aspecto principal do que houve dissimuladamente produzido pelo genro, mas que foi também aceito por Anne, por mais estranha que aquela situação parecesse. E ela aceita a explicação. "É o rapaz negro que discutiu com ele". Mas por que discutiu? Bem, existe até a possibilidade de uma história bastante feia naquele episódio envolvendo inclusive "humilhação", mas não importa: ele é um rapaz negro a ser evitado.

Anne incorpora um tipo social que Haneke quer trabalhar nesse filme: ela é francesa, atriz, branca, considerada bonita por todo mundo, que se diverte no trabalho e nos encontros com os amigos. Momentos antes de Anne notar a presença de Amadou no bar, ela interrompe bruscamente uma conversa sobre a guerra do Kosovo e a vida complicada na "civilizada" França para perguntar se uma amiga havia lhe trazido o endereço do dentista com o qual ela queria se consultar.

Construir esse tipo social como uma atriz é uma grande inspiração por parte de Haneke. Ele mostra duas filmagens de Anne atuando. Em um dos filmes, a atriz
Anne é vítima de um maníaco que a prende em um cômodo que libera gás aos poucos. Ela irá morrer e ele quer ver, pelo simples prazer de vê-la morrer. No segundo, ela está se divertindo em uma piscina com o seu marido e, ao notarem que o filho está no parapeito, correm para tirá-lo de lá, salvando a sua vida. Os únicos momentos - pelo menos até então - em que Anne está (1) em uma situação de violência ou (2) de ação efetiva diante de uma tragédia é no cinema, não na sua vida real.

$\mathrm{Na}$ vida real, ela escuta gritos de uma criança em um apartamento vizinho ao seu que lhe chamam a atenção. Em seguida, recebe uma carta de pedido de socorro de uma criança deixada no chão da sua porta. Ela discute com o seu namorado, Georges, em um supermercado, e reclama que ele não toma partido, que ele nunca faz nada, que ele nunca fez ninguém feliz. Há uma criança que ela acha que está morrendo e, para ela, o problema é que o seu namorado não faz nada, não ela. Cenas depois, ela vai ao enterro da criança.

No único momento em que ela toma uma decisão, Haneke resolve frustrá-la. Ela e Georges vão à casa do pai dele, pois o seu irmão havia sumido. O pai estava triste, mas era um homem do campo, retratado como bastante rude, retraído, carrancudo. Ela tenta acolhê-lo segurando a sua mão e ele imediatamente a recolhe e sai dando uma desculpa - entra aqui a questão da masculinidade, de não demonstrar sentimentos, afetividade. Aquela dor era muito próxima à Anne, tratava-se do seu sogro, então, ela se importava. Já com a vizinha, ela até se importava, mas queria que o namorado tomasse alguma iniciativa. Com relação ao problema envolvendo Amadou e Maria, aquilo 
era muito distante. É o que Dejours (2007) chamaria de "retraimento da consciência subjetiva": o indivíduo se sensibiliza pelo mundo mais próximo, enquanto aquilo que não está imediatamente ligado a ele não lhe desperta nenhum interesse.

Mas Haneke não é simplista dividindo bons e maus, opressores e oprimidos. Quando o filme vai para a Romênia, Maria se emociona ao contar quão mal estava se sentindo por causa de recordações de duas situações: uma em que ela teve nojo de uma cigana que lhe deu dinheiro e outra em que um francês deu-lhe dinheiro sem querer tocá-la (curioso que o espectador fica na expectativa de que ela iria relatar a cena inicial do filme, mas é claro que Haneke não iria dar esse gostinho hollywoodiano). Ou seja, humanos são sempre humanos, mas quando se passa pela situação de vulnerabilidade, a capacidade de reflexão é aguçada, é possível ter empatia pelo outro. $\mathrm{O}$ que parece ser verdadeiro no caso de Maria e de Amadou, mas não no de Jean ou de Anne.

Enfim, chega a cena clímax, em que entram dois jovens causando arruaça no metrô e um deles, mestiço, aborda Anne. Novamente, um take longo e que causa extremo desconforto: o jovem assedia Anne, ela não responde, ele pergunta se ela é modelo, dizendo que ela é muito bonita; ela não responde, ele pergunta se ela não fala com a ralé; ela muda de lugar, ele a segue, senta ao lado dela, em silêncio. Ao final, ele cospe na cara dela e sai correndo. Um senhor ao lado chuta o rapaz, que volta, parece que vai se armar uma confusão, que não se arma. Ela começa a chorar e agradece ao senhor que chutou o rapaz. Com um sarcasmo nas alturas, Haneke une o final dessa cena a um ensaio de bateria hipermulticultural e mul- tirracial - que já havia mostrado em outros momentos do filme.

Voltando à cena do metrô: Anne é assediada. Isso é uma violência. Contudo, a cena precisa ser lida dentro do filme, no simbolismo que o concatenamento de ideias e imagens nos traz: novamente, é uma situação em que ela se cala. Ela não se comunica com o rapaz. E ele pergunta com todas as letras: "Você não fala com a ralé?". A verdade é que a resposta que o filme dá a essa pergunta é "não, a Anne não se comunica com a ralé, de fato", além do fato de que ela agradece ao senhor que chuta o rapaz quando a situação já tinha se resolvido: o rapaz estava saindo do vagão. Lendo simbolicamente, temos um mundo tentando se comunicar com outro. No plano individual, temos uma mulher com medo de um rapaz. Do lado de quem sofre racismo e xenofobia diariamente, há uma gama de violências que nem é necessário detalhar. Do lado dela, há o medo de uma violência potencial que gera um fechamento sobre si mesma, o que - tenho a impressão de que essa é a triste conclusão do diretor nesta cena - não vai salvá-la da violência produzida pelo seu próprio comportamento, por mais inocente que ele possa parecer: um desprezo no nível individual pode ser uma desilusão amorosa; o mesmo desprezo multiplicado no comportamento de uma parcela de uma sociedade sobre outra parcela pode atender pelo nome de racismo, xenofobia, etc.

\section{CACHÉ (2005)}

Caché é um thriller que ganhou diversos prêmios e foi eleito como melhor filme da década dos anos 2000 pelo jornal The Ti- 
mes. A princípio, o espectador é envolvido para tentar descobrir quem seria o psicopata que atormenta a pobre família inocente com aquele sadismo psicológico, até que se começa a perceber que se trata de algo muito grave ocorrido há bastante tempo.

Assim como em Código desconhecido, Caché conta com o casal Anne e Georges. Não creio que seja um detalhe fortuito. Anne é novamente interpretada por Juliette Binoche, mas Georges é aqui interpretado por Daniel Auteuil. Não sou crítico de cinema, mas mesmo com todos os prêmios que o filme recebeu, sinto que ele perde muito com essa atuação pouco convincente. Tenho a impressão de que Auteuil está nesse papel porque Haneke precisava de um ator com o nariz torto, por uma briga que teria tido com Majid (interpretado por Maurice Bénichou), conforme se sabe no decorrer do filme.

Em Código desconhecido, Georges não tem sobrenome. Anne é a pessoa que se recusa a observar os conflitos no seu entorno, se esquiva de tomar decisões importantes e só se interessa pelas superficialidades ao seu redor. Já Georges é o namorado fotógrafo de guerra. Em Caché, o casal é Georges e Anne Laurent. Georges é a pessoa que não apenas se esquiva de tomar decisões importantes: também se recusa terminantemente a avaliar o seu passado e o mal que pode ter causado. Já Anne é a pessoa que passa a questionar o que Georges fez quando percebe que ele pode ter causado um grande sofrimento a alguém.

Georges Laurent e sua esposa têm uma vida tranquila. Ele tem um programa de televisão em que discute literatura e possui uma audiência considerável. Ela trabalha em uma editora e tem um caso com o chefe. Eles têm um filho chamado Pierrot. Logo passam a receber algumas fitas VHS com imagens da própria casa; depois, da casa em que Georges cresceu. Recebem também cartões com imagens de crianças vomitando sangue e de um galo sangrando no pescoço. Todos desenhos que parecem feitos por crianças. As câmeras estão escondidas, a pessoa atormentando a família está escondida, os motivos são desconhecidos. Parece ser essa a questão a ser desvendada, tal é o título do filme.

Enfim, em uma das fitas consta uma localização, um caminho que vai de uma rua da periferia de Paris até um quarto de um edifício, e precocemente começamos a entender os significados daquilo tudo e que a trama se desenvolverá de outra maneira. Quando chega à casa, Georges encontra-se com Majid, que conhece, e pergunta o que ele quer com as fitas e os desenhos. Majid afirma não ter mandado as fitas ou desenhos. Georges diz para Majid ficar longe da sua família e o ameaça.

Essa conversa entre Majid e Georges também estava sendo gravada e é enviada à casa de Anne e Georges e ao seu trabalho. Para Anne, Georges explica tudo o que tinha ocorrido: que conhecia aquele senhor, ele era o filho de algerianos ex-empregados dos seus pais, que sumiram no massacre de 1961, quando a Frente de Libertação Nacional dos Algerianos convocou a passeata histórica em Paris. Explica que, depois que os pais de Majid morreram, os seus pais tinham decidido adotá-lo. Sendo contra, por não querer dividir o quarto, Georges, aos seis anos, passou a inventar mentiras sobre o menino.

Depois, chamado pelo patrão, que queria saber sobre o conteúdo daquela fita (já que 
Georges ameaçava Majid na gravação), Georges diz que Majid tem um ódio patológico pela família dele, à qual vinha aterrorizando havia meses. E como é de costume comprar a versão de quem se é mais próximo, o chefe diz ser uma situação desagradável e pergunta se Georges já chamara a polícia, recomendando que procurasse um advogado. Quando pergunta sobre os motivos daquele vídeo, Georges responde não fazer ideia; que Majid tem certeza de que ele e sua família o teriam maltratado, e o pior: a última vez que o vira tinha sido aos seis anos de idade. Comovido, o chefe diz que aquilo que Georges está passando é um horror.

O que está escondido não é mais nem a câmera, nem quem fez os desenhos, nem um maníaco querendo apavorar uma família: agora é o relacionamento extraconjugal de Anne percebido pelo filho Pierrot (há toda uma questão secundária a esse respeito no filme), é a vida que Georges destruiu deliberadamente quando tinha seis anos.

Entretanto, Georges tem razão a respeito de uma coisa: a criança de seis anos pode não perceber a gravidade do que está fazendo. Crianças fazem isso, crianças são egoístas, podem ser perversas; crianças mentem e por vezes não medem as consequências para conseguir o que querem. O problema é a incapacidade de analisar, como adulto, as consequências das suas atitudes. O comportamento aos seis anos, embora reprovável, pode ser compreensível. Contudo, eticamente inconcebível é não rever, em nenhum outro momento da vida, o que aquilo pode ter resultado. E mesmo sendo obrigado a ver a dor e o sofrimento, ele apenas consegue repetir que tinha seis anos quando tudo aconteceu, que precisa trabalhar, que não tem tempo para aquilo.
De alguma forma, seu comportamento aproxima-se do que Arendt (1999) escreveu a respeito de Eichmann: a sua dificuldade de falar tinha a ver com a sua dificuldade de pensar, pensar no lugar do outro, de sentir empatia; além de que estava sempre obedecendo a ordens. Eichmann obedecia às ordens do Estado. Já os cidadãos modernos obedecem a ordens de cronogramas, horários, metas, o que dificulta o pensamento crítico e facilita o subterfúgio quando a questão é mais espinhosa.

Majid o chama novamente ao seu apartamento, desta vez para assistir ao seu suicídio. Em uma cena rápida, Majid saca um canivete e corta o próprio pescoço, lavando a parede com sangue. Georges sai da casa, anda por horas a fio pela cidade; volta para casa, conta para Anne que Majid havia se matado e explica as mentiras que tinha contado aos pais, por insistência de Anne: ele dizia à mãe que Majid tossia e expelia sangue. Depois, disse a Majid que o pai queria que ele matasse um galo do local em que viviam. Ele o fez e ficou coberto de sangue; então, Georges chamou o pai e disse que Majid queria assustá-lo. Com isso, decidiram mandá-lo para um orfanato, o que acabou com a sua vida. Aí, conclui o incidente daquele dia para Anne: "Cortar a própria garganta por isso é brincadeira de mau gosto, não acha?". Do seu ponto de vista, é uma brincadeira de mau gosto com ele. O sofrimento do outro pouco importa. Bem, não há a menor dúvida de que Majid queria chamar a atenção de Georges para a sua dor, mas Georges esqueceu a parte da dor e reteve apenas a parte que Majid fazia questão de compartilhar: uma desgraça que também dizia respeito a uma pessoa que estava totalmente alheia a ela: no caso, ele. 
Em seguida, o filho de Majid (interpretado por Walid Afkir) segue Georges no seu trabalho. Georges diz que não tem tempo para ele, mas o filho chama a atenção de toda a empresa e Georges o leva para uma conversa no banheiro. Ele quer resolver logo aquela questão, saber as intenções do rapaz. Enfim, Georges diz que nunca se sentirá culpado pela vida infeliz que Majid teve. Pragmaticamente, como sempre, pergunta o que o rapaz quer e ele responde que só queria saber como era viver com a consciência de Georges. Georges sai do banheiro, do escritório, volta para casa, toma dois comprimidos, se fecha em um quarto escuro e dorme.

Hannah Arendt (1999) refletiu sobre como a razão de Estado poderia blindar os indivíduos das suas responsabilidades éticas, afinal, se um oficial do Estado faz determinada coisa, ele estaria obedecendo a ordens, seja comandar uma repressão ou exterminar judeus, como foi o caso de Eichmann. Alguns autores, como Todorov (1995), Bauman (1999) e Dejours (2007), tratam de comportamentos modernos que podem apresentar, em algum gênero, embora em grau menor, algumas condutas parecidas. Tanto em Código desconhecido quanto em Caché, Haneke parece querer trabalhar essa "conduta de vida não reflexiva". A Anne de Código desconhecido ignora o que a rodeia com maior ou menor esforço, dependendo da situação. $\mathrm{O}$ Georges de Caché se infantiliza ao repetir que é normal o que ele fez quando tinha seis anos, como se ainda fosse criança, e se recusa a sentir-se responsável pelo que fez. Anos tinham se passado e a sua vida seguia com a tranquilidade burocrática de uma família pequeno-burguesa francesa qualquer. Mas, mesmo quando chegam todos os indícios de que ele teria desgraçado uma vida e não tinha tomado nenhuma atitude com relação àquilo posteriormente, ele se recusa a se colocar no lugar do outro. Mesmo quando Majid se suicida, não lhe passa pela cabeça o sofrimento, a dor de uma vida. Tudo o que ele cogita é que foi uma "brincadeira de mau gosto" com ele.

Afinal, ele sabia que não precisaria se preocupar. Mesmo depois da morte de Majid, o seu filho ainda tenta fazê-lo ver que, se havia alguém que deveria se responsabilizar pela desgraça daquela vida, era ele. Mas Georges sabia que não seria enforcado como Eichmann. A polícia constatou que Majid tinha se suicidado e que, apesar de presente no momento, Georges "não tinha responsabilidade". Então, depois de um dia tumultuado como aquele com o filho de Majid, dois comprimidos e um quarto escuro são suficientes para descansar e aguentar o dia seguinte de gravação e edição do seu programa sobre os mestres da literatura francesa e seguir a sua vida de homem honrado e espirituoso, aquele tipo que gosta de dizer em entrevistas: "Não me arrependo de nada do que fiz, só do que não fiz".

\section{A FITA BRANCA (2009)}

O filme é narrado por um professor que conta os acontecimentos ocorridos no vilarejo em que morou quando tinha 31 anos, antes de começar a Primeira Guerra Mundial. Começa dizendo que tais acontecimentos "poderiam esclarecer algumas coisas que ocorreram neste país", a Alemanha. Obviamente, Haneke está fazendo uma referência ao nazismo, assim como no título do filme: a "fita branca" amarrada no braço 
de dois dos filhos do pastor do vilarejo é a maneira que ele usa para recordá-los da impureza que resulta dos seus pecados, o que nos lembra as marcas feitas nos judeus nos campos de concentração.

Haneke não está preocupado com os fatores políticos, históricos e econômicos do nazismo, mas com a reprodução entre gerações do orgulho da Herrenwolk (nação de senhores), da personalidade autoritária e da Schadenfreude, ou seja, a satisfação pelo sofrimento de outra pessoa ou, ainda, a sociabilidade típica das confrarias alemãs que tinham horror à piedade e à compaixão. Também se trata de uma sociedade protestante, portanto, uma sociedade com uma disciplina mundana consideravelmente mais rígida do que as sociedades católicas, além da proximidade com o século XIX, aquele em que houve, digamos, uma cruzada contra o onanismo, ou seja, a masturbação; cruzada que estava vinculada à ideia não apenas de pureza, mas também de raça. Tudo isso misturado faz com que a cena-chave - e a mais impressionante - seja a do pastor exigindo a confissão do seu filho Martin (com a esplêndida atuação do jovem Leonard Proxauf):

“- ... sua mãe e eu ficamos muito preocupados com você. Pense bem. Você dormiu mal? Está cansado?

- Não.

- Tem problemas na escola que eu não saiba? - Não, pai.

- Você não entende por que nos preocupamos. Vou lhe explicar. Como sabe, também sou o pastor em Birkenbrunn. Um dia, uma mãe veio me ver com o filho que tinha a mesma idade que você e os mesmos sintomas que você vem mostrando ultimamente.
O garoto, de repente, apareceu extremamente fatigado. Seus olhos tinham olheiras, estava deprimido e sem alegria. Ele evitava olhar seus pais nos olhos, e logo, ele também caiu doente. Isso continuou por meio ano. Então, tudo aconteceu muito depressa. Ele perdeu o apetite, não conseguia mais dormir, suas mãos começaram a tremer, sua memória começou a falhar, seu rosto se encheu de pústulas, e depois o corpo todo. Finalmente, ele morreu. O corpo, que eu havia abençoado, parecia o de um homem velho. Entende agora por que me preocupo? O que você acha que causou aquelas mudanças que levaram o garoto a ter um fim tão miserável?

- Não sei.

- Acho que você sabe muito bem. Não vai me dizer? Não? Então vou lhe dar a resposta. $\mathrm{O}$ garoto tinha visto alguém, que danificou os mais delicados nervos do seu corpo, na área onde Deus levantou sagradas barreiras. $\mathrm{O}$ garoto repetia esse gesto. Ele não conseguia parar mais. No final, ele destruiu todos os seus nervos e morreu disso. Só quero ajudar você. Eu amo você com todo o meu coração. Seja sincero, Martin. Por que você ficou ruborizado ao ouvir a história do pobre garoto?

- Ruborizado? Não sei. Senti pena dele.

- Só isso? Acho que existe um outro motivo. Está escrito no seu rosto. Seja sincero. Martin! Por que está chorando? Devo poupá-lo de uma confissão? Você tem feito a mesma coisa que aquele pobre coitado?

- Sim”.

O filho confessa e passa a dormir com os braços amarrados à noite. Foucault nos diz que, historicamente, existem duas maneiras de produzir a verdade do sexo: (1) pela ars erotica do Oriente, cuja 
verdade se extrai da própria experiência, e (2) pela scientia sexualis do Ocidente (sim, ele trata de uma maneira problemática as ideias de "Oriente" e "Ocidente", mas importa o que ele fala sobre a racionalização ocidental do sexo), tratando-a como segredo para que possa ser exposta em forma de confissão. A sociedade ocidental é uma sociedade confessional, seja ela considerada pelo seu caráter religioso, seja pela necessidade de se falar, falar incessantemente do sexo nos meios científicos para a perscrutação do motor da degenerescência moral causada pelos seus vícios. Mas, por outro lado, o ritual de confissão tem também o sentido da purificação e da salvação (Foucault, 1988). E o mais importante: a possibilidade de sistematizar a conduta biológica em termos de longevidade, força, vigor, saúde. O "dispositivo da sexualidade" está em consonância com a proteção da vida familiar e social, uma vez que seria a descendência sadia o que protegeria a raça.

Foucault entende o período entre o XVII e o XIX como aquele de maiores proibições e contenções sexuais. $\mathrm{O}$ século XX seria o de afrouxamento dos mecanismos de repressão. Contudo, claro, esse afrouxamento ocorre no decorrer do século e o filme retrata as suas primeiras décadas.

E por que, no século XVII, inicia-se uma série de regulações e proibições? Bem, isso é bastante teórico, mas em linhas gerais, pode-se dizer que, para Foucault, é a primeira vez na história em que o Estado se preocuparia em governar a população. $\mathrm{Ou}$ seja, bem grosseiramente, antes o Estado era soberano, acumulava ouro e defendia as suas fronteiras; a partir desse momento, ele passaria a se ocupar do aspecto biológico da sua população - fazê-la viver mais, aumentá-la, pois o seu trabalho passaria a ser o elemento que criaria riqueza ao reino. É a emergência da biopolítica, que tem as funções de prevenir, localizar os indivíduos nos espaços para protegê-los, discipliná-los e regulá-los (seriam os aspectos negativos do poder), mas também de intervir nos corpos para produzir verdades e potencializar resultados (aspectos positivos do poder) (Foucault, 2008).

Ao invés de impor austeramente os mecanismos de controle sexual ao proletariado para impedir o desperdício de energias para que elas fossem direcionadas ao trabalho, as classes dirigentes aplicaram em si mesmas as técnicas mais fortes de recrudescimento austero das suas atividades sexuais. Daí se compreende a sequência lógica em que o pastor afirma amar o filho e força a confissão. Martin é parte da linhagem sadia; seu pai tem a função de gestão do seu corpo para protegê-lo e preservá-lo. Por isso, "suscita" a sua sexualidade: isto é importante, ele a suscita, denomina, expõe os seus riscos, controla os seus efeitos amarrando os braços de Martin durante a noite para garantir a vitalidade e a progenitura. Afinal, o sexo foi considerado no decorrer dos séculos como campo de fragilidade patológica e o corpo das classes dominantes deveria afirmar a sua distinção.

Os castigos infligidos pelos pais do vilarejo são cruéis, as maneiras como pais e filhos se relacionam não demonstram nenhum afeto; nem mesmo quando se diz que se ama, não existe nenhuma afeição além da palavra. As relações são de hierarquia, punição, penitência e disciplina, como pareciam ser caracterizadas as sociedades protestantes até há pouco tempo. Quando a baronesa anuncia ao marido sua saída de 
casa, ela justifica que iria embora para que os filhos não crescessem em um ambiente dominado pela "maldade, inveja, indiferença e brutalidade". Mesmo o mais atencioso cuidado com os filhos pode contraditoriamente ser completamente indiferente e brutal. E essa indiferença e brutalidade são a maneira como a nova geração lidará com o mundo, pois é a maneira como aprendeu a enxergá-lo. Há a necessidade de falar sobre a sexualidade, enquanto o mundo afetivo, embora verbalmente expresso, é totalmente obscurecido.
A partir desse ponto, não é mais difícil entrever, como conclusão, uma relação importante: sexo e sangue, vida e raça, força e distinção. A biopolítica, nesses termos, assume uma feição de hierarquização social, uma necessidade de proteção da pureza em nome do sangue. Aqui reside a fita branca que o pastor havia posto, anteriormente à cena da confissão, no braço dos seus filhos para lembrá-los da sua pureza perdida. Assim não há mais antagonismos entre esse frio amor paterno, a religiosidade ascética, o controle sexual e o genocídio.

\section{REFERÊNCIAS}

ARENDT, H. Eichmann em Jerusalém. São Paulo, Companhia das Letras, 1999.

BAUMAN, Z. Modernidade e ambivalência. Rio de Janeiro, 1999.

DEJOURS, C. A banalização da injustiça social. Rio de Janeiro, Editora FGV, 2007.

FOUCAULT, M. História da sexualidade: a vontade de saber. Vol. 1. Rio de Janeiro, Edições

Graal, 1988.

FOUCAULT, M. Segurança, território, população: curso dado no Collège de France (1977-1978).

São Paulo, Martins Fontes, 2008.

SPECK, O. Funny frames: the filmic concepts of Michael Haneke. Nova York/Londres,

Continuum, 2010.

TODOROV, T. Em face do extremo. Campinas, Papirus, 1995. 